
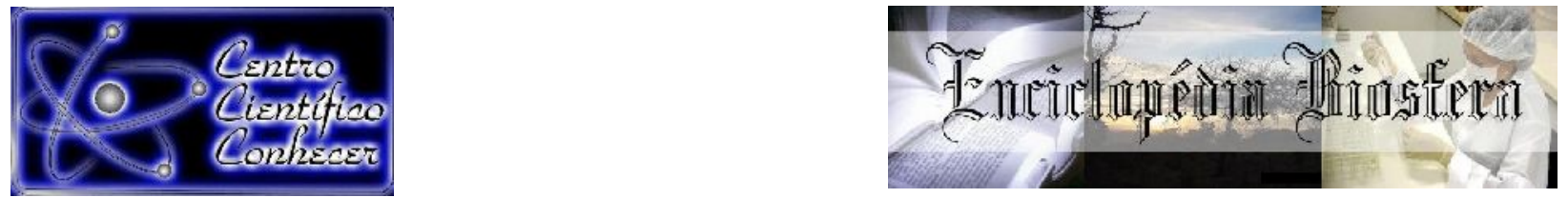

\title{
USO DE JOGOS DIDÁTICOS COMO ESTRATÉGIA PARA O ENSINO DE EDUCAÇÃO SEXUAL NO ENSINO MÉDIO
}

\author{
Lorena Ziviani Bevitório', Marcos de Lucca Moreira Gomes², Juliana Castro Monteiro \\ Pirovani $^{3}$ \\ 'Mestre em Biodiversidade Tropical da Universidade Federal Espírito Santo \\ (UFES/CEUNES), São Mateus-ES, Brasil. \\ 2Doutor em Biologia Celular e Estrutural, Professor da Universidade Federal do \\ Triângulo Mineiro (UFTM), Uberaba-MG, Brasil. \\ ${ }^{3}$ Doutora em Biologia Celular e Estrutural, Professora da Universidade Federal \\ Espírito Santo (UFES/CEUNES), São Mateus-ES, Brasil. \\ E-mail: julianacmonteiro@gmail.com
}

\section{Recebido em: 04/10/2019 - Aprovado em: 30/11/2019 - Publicado em: 15/12/2019}

DOI: 10.18677/EnciBio 2019B57

\begin{abstract}
RESUMO
A sexualidade é inerente ao ser humano e se faz presente na vida, principalmente, dos adolescentes. A escola, juntamente, com a família, exerce um papel fundamental na disseminação do conhecimento a respeito deste tema. Entretanto, é um assunto pouco explorado em sala de aula, pois ainda é considerado um grande tabu. Além disso, a carência de metodologias modernas e suporte teórico para os professores aumentam o desafio sobre o ensino da educação sexual para adolescentes. Portanto, o presente estudo avaliou a contribuição de jogos didáticos no processo de ensino-aprendizagem utilizando temas relacionados à Educação Sexual. Foram utilizados três jogos didáticos do projeto Vale Sonhar, um questionário semiestruturado e realizado um grupo focal. Os jogos favoreceram a aprendizagem, tornando as aulas atrativas aos estudantes ao estimular a competição entre os alunos, garantindo o interesse pelos temas abordados. Portanto, os jogos utilizados apresentaram-se eficientes no ensino-aprendizagem de temas relacionados à Educação Sexual.
\end{abstract}

PALAVRAS-CHAVE: Adolescência, projeto Vale Sonhar, sexualidade

\section{USING DIDACTIC GAMES AS A NEW APPROACH TO TEACH SEX EDUCATION IN HIGH SCHOOL}

\section{ABSTRACT}

Sexuality is inherent in the human personality throughout life, especially in teenagers. The school, along with the family, plays a key role in the dissemination of knowledge around sexuality. However, such subject is still poorly explored within the classroom, being also considered a taboo. Furthermore, the lack of modern methods and theoretical support for the teachers increases the challenge of teaching sex education for teenagers. Therefore, the aim of the present study was to evaluate the contributions of educational games in the teaching-learning topics related to sexual education during high school. Three didactic games from the project Vale Sonhar, a semi-structured questionnaire and a focus group were employed. The games 
provided a favorable environment for learning, turning the school attractive to students by enhancing competition among them, ensuring interest to the addressed themes. Therefore, the games were efficient in the teaching-learning topics related to sexual education.

KEYWORDS: Youth, sexuality, Vale Sonhar project

\section{INTRODUÇÃO}

A adolescência é uma fase marcada por grandes transformações biológicas, psicológicas e sociais (LARA; ABDO, 2015). Mais precisamente, entende-se adolescência como período de desenvolvimento entre a infância e a idade adulta (SCHOEN-FERREIRA, 2010). Aspectos relacionados à sexualidade assumem posição de destaque neste período, tornando-se imprescindível o acompanhamento dos adolescentes por parte dos pais e da escola a fim de contribuir para o desenvolvimento saudável do indivíduo (LARA; ABDO, 2015; PALMA et al., 2015).

Devido às mudanças comportamentais dos jovens a partir da década de 70 , a discussão sobre a inclusão da temática sexualidade no currículo das escolas aumentou. A partir da década de 80 , os trabalhos sobre sexualidade nas escolas intensificaram-se, devido à preocupação com o risco de infecção pelo vírus da Imunodeficiência Humana (HIV) e a grande incidência de gravidez entre adolescentes (BRASIL, 1998).

Dois termos relacionados à sexualidade são comumente trabalhados na escola: educação sexual e orientação sexual. Apesar do termo orientação sexual ser utilizado nos Parâmetros Curriculares Nacionais (PCN), neste estudo optou-se por utilizar o termo "educação sexual" por considerá-lo mais abrangente. Deste modo, consideramos que a expressão orientação sexual diz respeito ao desejo sexual do indivíduo (CARRARA, 2015; PALMA et al., 2015). De acordo com o PCN, a sexualidade deve ser trabalhada como tema transversal, isto é, tanto a concepção quanto os objetivos e conteúdos propostos por Orientação Sexual devem ser contemplados pelas diversas áreas do conhecimento em todos os anos da escolarização básica (BRASIL, 1998; PALMA et al., 2015).

O aperfeiçoamento de técnicas didáticas para auxiliar o docente ao longo do processo de ensino-aprendizagem desde o ensino básico culminou no uso de diversos recursos que aumentam a atenção, o envolvimento e o prazer em aprender. Neste contexto, os jogos são atividades lúdicas que podem ser utilizados como promotores da aprendizagem, conduzindo e desenvolvendo a habilidade na resolução de problemas, favorecendo a apropriação de conceitos e a atendendo as peculiaridades da adolescência (MARTINS; BRAGA, 2015; NICOLA; PANIZ, 2016). Assim, o contexto lúdico apresenta-se favorável ao aluno, estimulando o domínio de si, a criatividade, a afirmação da personalidade e o imprevisível.

Para Piaget (1978), as atividades lúdicas são de extrema importância para o desenvolvimento humano porque propiciam ao indivíduo o respeito às regras, a expressão do imaginário, a apropriação do conhecimento, além do desenvolvimento intelectual, cognitivo, psíquico e motor. O jogo é uma atividade lúdica, pois se joga pelo simples prazer de realizar esse tipo de atividade, além de desempenhar o aspecto físico e mental organizada por um sistema de regras (VOLPATO, 2017).

O uso e a importância dos jogos também são descritos nas Orientações Curriculares para o Ensino Médio, que direcionam o valor dos jogos para o desenvolvimento cognitivo dos alunos (BRASIL, 2006). Entretanto, o jogo nem 
sempre foi visto como material didático, pois como a ideia de jogo encontra-se ligada ao prazer, ele era julgado como sendo pouco importante para a formação do aluno. Sendo assim, a utilização do jogo como meio educativo demorou a ser aceita no ambiente educacional (VOLPATO, 2017). Até os dias de hoje podemos perceber que os jogos didáticos são pouco explorados e seus benefícios, muitas vezes, são desconhecidos por muitos professores.

Moraes et al. (2019) verificaram ao aplicar jogos do projeto Vale do Sonhar para o Ensino Fundamental, que o uso dos jogos didáticos proporcionou a aproximação entre conteúdo e o cotidiano do aluno, sendo importante para a assimilação dos conteúdos relacionados à educação sexual. Além disso, esses autores afirmam que quando a escola desempenha seu real papel formativo, jovens tendem a desenvolver valores, competências e conhecimentos que lhes permitem a realização de escolhas responsáveis, quer em suas vidas sociais, quer estritamente na vida sexual.

Diante do exposto, é notável que a escola exerce um papel fundamental na disseminação do conhecimento a respeito de sexualidade de uma forma clara e que inclua não só aspectos anatômicos e fisiológicos, mas também aspectos sociais, psicológicos e culturais. Entretanto, poucas as escolas se interessam em trabalhar este tema de forma lúdica e interativa. Na maioria dos casos, passam o conteúdo de forma limitada a conhecimentos biológicos, suprimindo questionamentos e dúvidas, sem acrescentar a isso componentes emocionais e afetivos. Além disso, é notável a carência de metodologias e de suporte teórico para os professores que realizam trabalhos e induzem discussões sobre sexualidade.

Dessa forma, esse trabalho descreve as possíveis contribuições dos jogos didáticos como estratégia de recurso didático para o processo de ensinoaprendizagem de temas relacionados à Educação Sexual com adolescentes do segundo ano do ensino médio, onde a informação foi passada de uma forma lúdica, proporcionando interação e socialização perante o tema.

\section{MATERIAL E MÉTODOS}

A pesquisa foi desenvolvida com alunos de uma Escola Estadual, localizada no município de São Mateus, ES. Participaram da pesquisa 112 alunos, de quatro turmas do $2^{\circ}$ ano do Ensino Médio, de ambos os sexos, com idades entre 16 a 18 anos. O projeto foi aprovado pelo Comitê de Ética em Pesquisa (Registro no 34409714.6.0000.5063) do Centro Universitário Norte do Espírito Santo. Os participantes da pesquisa e/ou responsáveis assinaram o termo de assentimento (se menor de 18 anos) ou termo de consentimento livre e esclarecido (maiores de 18 anos e responsáveis dos menores).

Antes de iniciar a aplicação dos jogos foi realizado um levantamento com os alunos para estabelecer dúvidas e curiosidades sobre o conteúdo de Educação Sexual. Para isso, foi deixada uma caixa dentro da sala de aula para que os alunos depositassem suas dúvidas de forma anônima. Ao término da aula, as dúvidas foram separadas em categorias e quantificadas. Durante as aulas seguintes foram abertos espaços para os esclarecimentos das dúvidas deixadas pelos alunos.

Os jogos utilizados nessa pesquisa fazem parte do Projeto Vale Sonhar desenvolvidos pelo Instituto Kaplan, juntamente com os Laboratórios Pfizer, o Fundo Social de Solidariedade do Governo de São Paulo e a Secretaria de Educação do Estado de São Paulo. O projeto tem como objetivo oferecer suporte para alunos e professores sobre a prevenção da gravidez na adolescência promovendo a 
identificação do seu sonho e, assim, motivando os alunos sobre a importância da relação sexual responsável (INSTITUTO KAPLAN, 2007).

Para a aplicação dos jogos foram necessárias adaptações pontuais, visto que o tempo disponível para realização das atividades era inferior ao sugerido nas instruções dos jogos. Cada jogo foi aplicado em uma aula de 55 minutos, sendo que o recomendado é de 1 hora e 30 minutos. Apesar disso, a integridade e os objetivos propostos mantiveram-se inalterados.

Ao final de todos os jogos foi aplicado questionário aos alunos participantes, que avaliaram a atividade como recurso para o ensino-aprendizagem de Educação Sexual. Além disso, foi realizado um grupo focal com alunos selecionados aleatoriamente, sendo dois alunos de cada turma, totalizando oito alunos. O grupo focal teve o objetivo de promover a interação entre os participantes e o pesquisador, gerando dados qualitativos, a partir da discussão focada em tópicos específicos.

Neste trabalho, utilizou-se o método misto para a coleta de dados. A abordagem qualitativa foi fundamentada na análise de conteúdo de Bardin (1977).

O método misto conjuga ambos os métodos (quantitativo e qualitativo) de coleta e análise de dados. São utilizados métodos predeterminados das pesquisas quantitativas com métodos emergentes das qualitativas, bem como questões abertas e fechadas, com formas múltiplas de dados contemplando todas as possibilidades, incluindo análises estatísticas e análises textuais. Neste caso, os instrumentos de coleta de dados podem ser ampliados com observações abertas com maior profundidade. No método misto, o pesquisador baseia a investigação supondo que a coleta de diversos tipos de dados garanta um entendimento melhor do problema pesquisado.

Os dados foram analisados quantificando-se a frequência percentual das categorias apresentadas no questionário respondido pelos alunos. Além disso, foi feita análise do conteúdo das perguntas abertas do questionário e do grupo focal. Para as perguntas dissertativas presentes no questionário, organizaram-se as categorias que surgiram em frequências percentuais. Algumas falas dos alunos durante o grupo focal foram citadas e estes foram referidos como alunos $M 1, M 2$, M3, M4, M5, M6, M7, M8.

Sequências didáticas

Jogo "Nem toda relação sexual engravida"

O jogo aborda o conteúdo de anatomia e fisiologia dos sistemas genitais masculino e feminino através de perguntas e respostas e a identificação das práticas sexuais de riscos e tabus relacionados a estas práticas.

Para realizar esta atividade a turma foi dividida em grupos. Em seguida, iniciou-se o jogo com uma rápida competição: foi pedido aos alunos que relacionassem todos os tipos de carinhos e práticas sexuais que conheciam e, ao final dessa rodada, foi pedido ao representante de cada grupo para ler em voz alta o que tinha sido escrito. O grupo com maior número de itens foi o grupo vencedor desta pequena competição. Posteriormente, foi pedido aos alunos que identificassem na lista feita por eles os tipos de carinhos e práticas sexuais que oferecem risco de gravidez e contágio de infecções sexualmente transmissíveis (IST). Depois disso, foi pedido que os grupos guardassem as listas que seriam novamente utilizadas no final da aula. Na sequência, os sistemas genitais masculino e feminino interno e externo foram expostos e realizada uma breve explicação sobre cada um deles. O jogo teve início pelo grupo vencedor da competição anterior. As 
perguntas foram alternadas em sistema genital masculino, feminino e práticas sexuais. Para responder as perguntas de práticas sexuais os alunos tinham que se dirigir aos quadros dos sistemas genitais expostos e utilizar na sua explicação os cartões imantados (óvulo e espermatozoide). Havia a opção de responder a questão ou passar a questão para o próximo grupo. A pontuação foi definida da seguinte forma: a cada resposta correta ganhava-se 2 pontos, a cada resposta errada perdiase 2 pontos e quando se passava a vez nenhum ponto era computado. Ao final do jogo, ganhou o grupo que somou mais pontos. Por fim, os alunos reavaliaram as práticas que eles haviam anotado inicialmente: possuíam ou não risco de gravidez e contágio de IST? Com o conhecimento adquirido durante o jogo, fizeram adequações quando necessário.

Jogo "Engravidar é uma escolha"

Esse jogo contém perguntas e respostas relacionadas aos métodos contraceptivos e ao uso dos mesmos.

Inicialmente, foi feita a seguinte pergunta para a turma: o que são métodos contraceptivos e para que servem? Após as respostas, foram realizadas as complementações necessárias. Os cartões de métodos contraceptivos foram divididos em categorias [barreira, naturais, dispositivo intrauterino (DIU), cirúrgicos e químicos]. Em seguida, a turma também foi dividida em grupos. Foi entregue a cada grupo um conjunto de cartões e uma ficha de avaliação, onde foi avaliado de $0-10$ cada método contraceptivo, de acordo com a eficácia e acesso aos jovens. Assim que os grupos terminaram de avaliar aquele conjunto de métodos, foram realizados rodízios entre os grupos para que cada grupo pudesse avaliar todas as categorias. Ao final dessa etapa foi pedido que guardassem a ficha de avaliação, que seria utilizada, novamente, após o término do jogo. Na sequência, iniciou-se o jogo de perguntas e repostas. As perguntas eram direcionadas a cada grupo e tinham 1 minuto para discutir as questões antes de respondê-la. Caso o grupo errasse ou não soubesse a resposta, o próximo grupo teria o direito de resposta. A cada resposta correta era atribuído um valor de pontos referentes à cor do envelope de onde eram retiradas as perguntas. A cada erro, o grupo recebia uma carta risco e perdia 3 pontos ao final da jogada, por cada carta risco adquirida. $O$ grupo vencedor foi aquele que acumulou mais pontos. Ao final da competição, os alunos reavaliaram as pontuações atribuídas à ficha de avaliação dos métodos contraceptivos com 0 conhecimento que adquiriram durante a atividade.

Jogo "O despertar para o sonho"

Esse jogo permite que os adolescentes façam uma viagem ao futuro, podendo sonhar e construir seu projeto de vida, trabalhado o impacto da gravidez não planejada na adolescência.

Foi entregue uma ficha para cada aluno onde responderiam a seguinte pergunta: "qual é o meu sonho de vida profissional?" Em seguida, foi passado para os alunos um saco contendo fitas que representavam testes de gravidez que poderiam ser positivos ou negativos. Cada aluno retirou uma fita. Os alunos que tiraram positivo receberam uma bexiga, que foi colocada sob a blusa, simulando a gravidez. Dando prosseguimento ao jogo, foi pedido aos alunos que se posicionassem de forma confortável e que fechassem os olhos para iniciar a viagem ao futuro. Foi lido de forma pausada cada etapa do livreto "Viagem ao Futuro", fazendo perguntas durante a viagem para que os alunos pudessem imaginar as 
respostas. Após o retorno da viagem, foram feitos alguns questionamentos aos alunos como: "Como foi realizar esta viagem? Qual o impacto da gravidez na realização do sonho? E para os que viajaram sem estar grávidos, como foi a viagem ao futuro?". Em seguida, foi aberto espaço para discussão e debate sobre os relatos dos alunos.

\section{RESULTADOS E DISCUSSÃO}

\section{- Caixa de dúvidas}

A "Caixa de dúvidas" foi deixada na sala de aula para que os alunos depositassem suas dúvidas e curiosidades sobre o conteúdo de Educação Sexual. Durante essa atividade, foi possível perceber que alguns alunos ficaram inibidos, outros depositaram suas dúvidas sem constrangimento e outros pediram aos colegas para escreverem as suas dúvidas e depositarem na caixa, já que estavam envergonhados e não quiseram se dirigir até o local onde a caixa se encontrava. Após o término da aula, as dúvidas deixadas pelos alunos na "caixa de dúvidas" foram organizadas em categorias e quantificadas (Tabela 1). As dúvidas mais frequentes foram relacionadas às relações sexuais e excitação/prazer. Nas aulas seguintes, as dúvidas foram esclarecidas.

TABELA 1. Principais perguntas depositadas na "Caixa de dúvidas" pelos alunos

\begin{tabular}{|c|c|c|}
\hline Categoria & Quantidade & Perguntas \\
\hline Relações & & "Qual é o tamanho ideal que a mulher pode \\
\hline Sexuais & t & suportar na hora do sexo?" \\
\hline Excitação/Prazer & 7 & "Qual a posição a mulher sente mais prazer?" \\
\hline Ejaculação & 6 & "Esperma faz bem para pele?" \\
\hline Gravidez & 4 & $\begin{array}{l}\text { "Se a mulher engolir sêmen ela pode } \\
\text { engravidar?" }\end{array}$ \\
\hline Masturbação & 3 & "Masturbação dá espinha?" \\
\hline Menstruação & 2 & $\begin{array}{l}\text { "Quando a mulher está menstruada ela pode } \\
\text { engravidar ou isso é mito?" }\end{array}$ \\
\hline Orgasmo & 2 & "Como faz para a mulher ter orgasmo?" \\
\hline Virgindade & 2 & $\begin{array}{l}\text { "Por que quando as mulheres perdem a } \\
\text { virgindade ocorre sangramento?" }\end{array}$ \\
\hline
\end{tabular}

Fonte: dados da pesquisa

Pode-se perceber que os alunos possuem diversas dúvidas e curiosidades sobre os assuntos relacionados à sexualidade. Durante as aulas eles ficavam eufóricos, porém atentos, principalmente nos momentos em que as dúvidas estavam sendo esclarecidas. Em relação à discussão desses aspectos no âmbito escolar, o PCN diz que:

Com a inclusão da Orientação Sexual nas escolas, a discussão de questões polêmicas e delicadas, como masturbação, iniciação sexual, o "ficar" e o namoro, homossexualidade, aborto, disfunções sexuais, prostituição e pornografia, dentro de uma perspectiva democrática e pluralista, em muito contribui para o bem-estar das crianças, dos adolescentes e dos jovens na vivência de sua sexualidade atual e futura (BRASIL, 1998, p. 293). 
Diante das dúvidas que surgiram na "Caixa de dúvidas", ficou evidente que existe um déficit de informações para esses alunos, principalmente as advindas dos próprios pais, como indicado por alguns alunos durante o grupo focal, ao serem questionados se existe alguma forma de diálogo relacionado à sexualidade dentro de casa. Segundo eles:

M1: "Não tem diálogo, não falam de prevenção, apenas alertam para não fazer isso, pois vai ter consequências".

M3: "Muitos pais não conversam com seus filhos e também não querem que sejam passadas muitas informações, e muitas vezes os filhos desses pais que engravidam".

M4: "Meu pai fala só para não aparecer com filho dentro de casa".

ARAÚJO et al. (2015) ao revisarem estudos sobre o papel dos pais na educação sexual de adolescentes, afirmam que a comunicação entre pais e adolescentes sobre educação sexual auxilia na redução do comportamento de risco. Assim, a família deveria estar ciente que deve ser a primeira fonte onde seus filhos devem buscar informações e a ação da escola deve ser complementar à educação dada pela família. Entretanto, pela fala dos alunos durante o grupo focal, pode-se perceber que esse diálogo não tem acontecido em casa. A partir do silêncio encontrado em casa, o adolescente muitas vezes procura informações relacionadas à sexualidade com outros adolescentes também imaturos, contribuindo, dessa forma, para a prática sexual insegura (KRABBE et al., 2016). Portanto, a escola torna-se referência crucial para a formação destes adolescentes a respeito de sexualidade, sendo o único meio de informações seguras.

\section{- Jogo "Nem toda relação sexual engravida"}

Inicialmente, os grupos listaram todos os tipos de carinhos e práticas sexuais que conheciam. Em seguida, identificaram nesta lista os tipos de práticas sexuais que oferecem risco de gravidez e contágio de IST. Nesta etapa, a maioria dos grupos os identificou corretamente, entretanto ocorreram erros graves, como "sexo natural" e "sexo oral" sendo marcados como não oferecendo risco de gravidez e contágio de IST, respectivamente. Durante a aula, essas práticas sexuais foram discutidas e esclarecidas, deixando claro que sexo oral praticado sem o uso de preservativo não apresenta risco de gravidez, entretanto, existe o risco de contrair IST. Para o sexo natural, caso seja praticado sem o uso de preservativo, apresenta tanto risco de gravidez quanto de contrair uma ou mais IST. Ao final da aula, os grupos consertaram os erros existentes na lista.

$\mathrm{Na}$ sequência, os grupos responderam as perguntas relacionadas aos sistemas genitais feminino e masculino e identificaram as práticas sexuais que oferecem risco de gravidez. Durante o jogo, todas as turmas apresentaram dificuldade em responder questões relacionadas à função reprodutiva da secreção vaginal, diferença entre período e ciclo menstrual e número de espermatozoides que o homem elimina durante a ejaculação.

Em relação às práticas sexuais que oferecem risco de gravidez, os alunos demonstraram ter conhecimento e identificaram situações que apresentam risco de gravidez. Entretanto, disseram não ter conhecimento de algumas situações que apresentavam risco, como o coito interrompido, além de dificuldades em responder questões relacionadas ao líquido pré-ejaculatório, tempo de vida do espermatozoide fora do corpo do homem e possibilidade de gravidez durante a menstruação. 
O jogo proporcionou a interação entre os participantes do mesmo grupo e competição entre os diferentes grupos, além de promover a aproximação entre o educador e os alunos. Esse clima estimulou ainda mais os alunos a jogarem, pois sentiam-se desafiados pelo grupo adversário e faziam o possível para acertarem as perguntas. Benine (2010), ao aplicar o jogo "Nem toda relação sexual engravida" para alunos do ensino fundamental, verificou este mesmo clima de competição, proporcionando a disputa entre grupos adversários e a união entre componentes do mesmo grupo. Segundo a autora, esse clima foi favorável à aprendizagem, instigando os alunos a jogarem e a buscarem a resposta correta para as questões.

O uso dos jogos didáticos auxilia a aprendizagem por trabalhar e desenvolver a cognição (desenvolvimento da inteligência e da personalidade, fundamentais para a construção de conhecimentos); a afeição (desenvolvimento da sensibilidade e da estima e atuação no sentido de estreitar laços de amizade e afetividade); a socialização (simulação de vida em grupo); a motivação (envolvimento da ação, do desafio e mobilização da curiosidade) e a criatividade (MIRANDA, 2002). Os questionamentos que costumam surgir na prática dos jogos possibilitam a busca de múltiplas respostas que favorecem a troca de experiências, bem como a vivência de movimentos diversificados. As dúvidas que surgem no decorrer do jogo devem ser discutidas e esclarecidas em grupo, favorecendo a aprendizagem, que ocorre entre o diálogo e o conflito, na busca da superação do individualismo (VOLPATO, 2017).

Apesar de negativa aos olhares de alguns pedagogos e psicólogos, a competição nos jogos é inevitável. Com o aumento do espírito competitivo o aluno desenvolve estratégias a fim de superar seus limites e deficiências que o levem a vencer, passo importante para seu desenvolvimento social, intelectual e afetivo. Além disso, o adversário no jogo deve visto como parceiro que possibilita a realização do próprio jogo, não como inimigo a ser vencido ou aniquilado (VOLPATO, 2017).

\section{- Jogo "Engravidar é uma escolha"}

Nesta prática, inicialmente os alunos responderam a pergunta: "O que são métodos contraceptivos e para que servem?". A maioria dos alunos respondeu corretamente, porém não sabiam explicar detalhes sobre a variedade de métodos contraceptivos disponíveis. Sendo assim, foi realizada uma breve discussão sobre o assunto. Em seguida, os grupos de alunos responderam sobre os métodos contraceptivos, sendo que a maioria dos grupos respondeu corretamente. Entretanto, tiveram dificuldades em algumas questões, como: definição de coito interrompido e o por quê de não ser recomendado; pausa entre as cartelas de anticoncepcional oral e risco de gravidez em caso de relação sexual sem uso de preservativo durante esse período; tomar mais de uma pílula de emergência em um mesmo ciclo menstrual; uso do adesivo de hormônios e implante subcutâneo e como estes evitam a gravidez; definição de DIU e como este evita a gravidez; uso do diafragma e uso do método muco cervical. Pode-se perceber que muitos alunos não possuíam conhecimento da diversidade de métodos contraceptivos disponíveis no mercado, bem como a forma de usá-los.

Com intuito de agregar maior conhecimento à aula, foram levados para a sala de aula preservativos masculinos e femininos para que os alunos demonstrassem, durante o jogo, a forma correta de utilização dos mesmos. Os alunos acertaram a forma correta de utilização do preservativo masculino. Entretanto, ficou evidente que 
muitos alunos nunca tiveram contato com o preservativo feminino, uma vez que a maioria dos alunos não sabia como deveria ser colocado na vagina da mulher.

Durante o grupo focal pode-se comprovar a falta de conhecimento sobre os métodos contraceptivos. Ao questionar como o jogo "Nem toda relação sexual engravida" contribuiu para o conhecimento e aprendizado, tivemos as seguintes respostas:

M2: "Aprendi muita coisa sobre métodos contraceptivos que não é falado em casa". M3: "Nunca tive relação sexual e pude aprender a utilização de muitos métodos e relações sexuais que apresentam risco, como o coito interrompido, já sei que é de risco e não vou praticar".

M5: "Aprendi realmente muita coisa porque não converso sobre esse assunto em casa".

M8: "Os pais têm vergonha e os filhos também e durante os jogos aprendemos muita coisa sobre a variedade de métodos disponíveis".

Mais uma vez os alunos mencionaram que assuntos relacionados à sexualidade não são discutidos em casa. Como o aluno M8 citou, muitas vezes os pais sentem-se envergonhados, assim como os filhos, ou ainda, o diálogo pode não acontecer por falta de conhecimento dos próprios pais.

Assim como no primeiro jogo, foi perceptível o clima de competição entre os grupos. Esse clima instigava os participantes, pois eles se desafiavam para responder as questões corretamente e isso fazia com que se empenhassem cada vez mais para responder as questões de forma correta.

Oliveira et al. (2010), ao utilizar jogos didáticos no ensino do sistema genital e sexualidade humana com alunos do $8^{\circ}$ ano, constatou que os jogos são uma ferramenta eficaz, por tornarem as aulas atrativas aos estudantes, aumentando o entusiasmo em participar, competir e ganhar. Observou-se que o clima competitivo se demonstrou favorável ao aprendizado sobre um tema cercado de dúvidas e tabus.

Durante o jogo, em alguns momentos, ocorreram reclamações sobre atitudes dos colegas relacionadas às regras, gerando confusão entre os grupos. Nestes momentos, o jogo era interrompido e as regras eram relembradas de forma a ficarem bem estabelecidas, o que proporcionou o desenvolvimento do respeito às regras, percebido ao longo das demais partidas.

As atividades lúdicas auxiliam na aquisição de conhecimentos científicos de forma eficaz e significativa, com atitudes de respeito ao colega e às regras de jogo. Quando os alunos são capazes de respeitar as regras, o relacionamento com as outras pessoas melhora, além de favorecer a recuperação da autoestima, condições essenciais para que ocorra o aprendizado (MESSEDER NETO; MORADILLO, 2016).

\section{-Jogo "O despertar para o sonho"}

De acordo com a dinâmica proposta, os alunos deveriam responder a questão "Qual é o meu sonho de vida profissional?" antes de iniciar o jogo "O despertar para o sonho". As respostas resumiram-se em: terminar o ensino médio, em seguida ingressar no ensino superior; conseguir um bom emprego; ajudar os familiares; e, por fim, constituir uma família e ter filhos. Em suas respostas, os alunos citaram algumas profissões como sonho de vida, dentre elas: engenheiro(a), advogado(a), médico(a), policial civil e militar, professor(a) de educação física e jogador de futebol. Após a viagem ao futuro proporcionada pelo jogo, responderam outras questões propostas. Assim, para conseguir realizar o sonho profissional eles alegaram que 
precisam ter muita força de vontade e perseverança, estudar e trabalhar muito. $\mathrm{O}$ fato de não terem engravidado na adolescência facilitou a realização do sonho, entretanto, aqueles que fizeram a viagem ao futuro "grávidos" alegaram ter sido muito mais difícil realizar o sonho. Alguns disseram não ter conseguido realizar o sonho, outros disseram que sim, mas não no tempo previsto, que o sonho teve que ser adiado e uma minoria disse que conseguiu alcançar seus objetivos sem enfrentar dificuldades, mas com ajuda dos familiares. Pode-se perceber que os adolescentes sonham em fazer um curso superior e entrarem no mercado de trabalho qualificados para competir por um bom emprego e se realizarem profissionalmente. Eles querem alcançar uma vida financeiramente estável para proporcionar maior conforto aos seus familiares. Durante o jogo, eles puderam perceber que a gravidez na adolescência pode dificultar ou até mesmo impedir a realização do sonho, pois na maioria dos casos, as meninas deixam os estudos para cuidar do filho e os meninos para trabalhar e sustentar a família.

Vacari (2011) ao aplicar o jogo "O despertar para o sonho" para alunos do ensino fundamental constatou que esse jogo proporcionou aos alunos maior chance de construção do conhecimento e concentração durante as aulas e, ainda, conscientizou da importância de métodos contraceptivos para que uma gravidez na adolescência seja evitada.

Durante o grupo focal foi possível perceber que esses adolescentes não desejam ter filhos na adolescência, justamente por almejarem conquistar uma vida melhor. Alguns já vivenciaram de perto familiares e amigos passarem por esta situação e não querem passar por momentos semelhantes, pois acompanharam as dificuldades enfrentadas por esses adolescentes. Ao serem questionados sobre o jogo "Despertar para o sonho" eles disseram:

M1: "Meu primo engravidou uma menina aos 16 anos, e minha tia sempre avisava para usar camisinha, mas não adiantou, eu vi isso em casa, e não quero isso para minha vida, mas muitos na sala não pensam assim e a prática ajudou muito".

M2: "Nós sempre imaginamos a vida no futuro, mas nunca imaginamos com filho, a prática ajudou a pensar melhor que não seria fácil, apesar de ter ajuda dos meus pais, é muita responsabilidade, tem que trabalhar cedo e deixar de estudar".

M3: "Tem gente que acha que só acontece com os outros".

M7: "O despertar para o sonho foi muito importante, pois refletimos que com 16 e 17 anos, conseguir ter um filho é muito difícil, para estudar seria uma batalha, tem que sustentar o filho, trabalhar, não quero isso para minha vida agora".

M8: "Trabalhar, estudar, cuidar do filho, tem que deixar tudo naquele momento para cuidar do filho".

Apesar dos alunos demonstrarem através de suas falas que não querem ter filhos durante a adolescência, ficou claro durante a aplicação dos jogos que muitos não têm o conhecimento necessário para evitar gravidez e IST, reforçando, mais uma vez, a importância de se trabalhar essa temática no âmbito escolar. Oliveira et al. (2017) relatam a importância de tratar a temática sexualidade ao detectarem a falta de conhecimento dos jovens sobre o tema. Esses autores observaram que, apesar dos adolescentes terem acesso à fontes variadas, não apresentam informações consolidadas sobre as IST. A correta orientação sexual é um direito do jovem. Dela depende a maneira com que ele exercerá sua sexualidade de maneira saudável e responsável. 


\section{-Questionário após a sequência didática dos jogos}

Após a intervenção com as sequências de jogos didáticos foi aplicado um questionário onde os alunos deveriam avaliar as estratégias da utilização de jogos no ensino de Educação Sexual. Na avaliação dos alunos do processo de ensinoaprendizagem de Educação Sexual com a utilização dos jogos didáticos (Tabela 2), foi constatado que os jogos colaboraram de alguma forma para o aprendizado desse tema. A principal categoria citada pelos alunos foi melhor compreensão do tema, seguida por novos conhecimentos adquiridos durante o jogo.

Tabela 2. Avaliação dos alunos sobre o uso dos jogos didáticos como auxílio no processo de ensino-aprendizagem do conteúdo de Educação Sexual.

\begin{tabular}{|c|c|c|}
\hline Categoria & $\begin{array}{c}\text { Alunos } \\
(\%)\end{array}$ & Discursos \\
\hline $\begin{array}{l}\text { Melhor } \\
\text { compreensão }\end{array}$ & 29,4 & $\begin{array}{l}\text { Aluno 12- "Porque com um material mais específico } \\
\text { nos ajudou a entender melhor sobre o assunto". }\end{array}$ \\
\hline $\begin{array}{l}\text { Novos } \\
\text { Conhecimentos }\end{array}$ & 27,6 & $\begin{array}{l}\text { Aluno 9- "Porque eu não sabia de muitas coisas } \\
\text { sobre sexo, nem como evitar gravidez". }\end{array}$ \\
\hline $\begin{array}{l}\text { Esclareceu/tirou } \\
\text { dúvidas }\end{array}$ & 17,7 & $\begin{array}{l}\text { Aluno } 65-\text { "Porque com as aulas diferenciadas a } \\
\text { gente consegue tirar mais dúvidas". }\end{array}$ \\
\hline $\begin{array}{l}\text { Facilitou a } \\
\text { aprendizagem }\end{array}$ & 8,0 & $\begin{array}{l}\text { Aluno 91- "Porque é uma forma dinâmica de } \\
\text { aprende, o que torna o entendimento mais fácil". } \\
\text { Aluno 96- "Porque nós adolescentes levamos mais }\end{array}$ \\
\hline Divertido & 5,2 & $\begin{array}{l}\text { a sério as coisas que nos divertem e ao mesmo } \\
\text { tempo ensina". }\end{array}$ \\
\hline $\begin{array}{l}\text { Não é c } \\
\text { em cas }\end{array}$ & 4,4 & $\begin{array}{l}\text { Aluno 80- "Pois, tiramos dúvidas de um assunto } \\
\text { que não é abordado em casa". }\end{array}$ \\
\hline $\mathrm{R}$ & 2,6 & $\begin{array}{l}\text { Aluno 102- "Por que nos ajudou a pensar e a } \\
\text { refletir, e quando isso ocorre, aprendemos mais". }\end{array}$ \\
\hline Sim & 2,6 & - \\
\hline Descontraído & 1,5 & $\begin{array}{l}\text { Aluno 108- "Pois foi de um modo } \\
\text { descontraído". }\end{array}$ \\
\hline
\end{tabular}

Fonte: dados da pesquisa

Antunes (2014) defende o uso de jogos didático no processo de ensinoaprendizagem, já que o jogo estimula a aprendizagem e o desenvolvimento de forma prazerosa, além de facilitar o desenvolvimento pessoal, social e cultural.

Em relação à sequência de jogos aplicados, foi questionado qual jogo contribuiu mais para o aprendizado dos alunos. O jogo "Engravidar é uma escolha" foi o que os alunos mais gostaram, porém "O despertar para o sonho" e o "Nem toda relação sexual engravida" apresentaram uma frequência similar de aceitação (Tabela 3). Os alunos que optaram pelo "Engravidar é uma escolha", disseram ter gostado por terem conhecido muitas formas de métodos contraceptivos que não tinham conhecimento, além de terem aprendido a forma correta de utilização dos mesmos. 
Tabela 3. Avaliação dos alunos sobre o processo de ensino-aprendizagem de cada jogo didático aplicado.

\begin{tabular}{lcl}
\hline \multicolumn{1}{c}{ Categoria } & $\begin{array}{c}\text { Alunos } \\
(\%)\end{array}$ & \multicolumn{1}{c}{ Discurso } \\
\hline "Engravidar é & 59,8 & $\begin{array}{l}\text { Aluno 103- "Porque me mostrou métodos } \\
\text { anticoncepcionais que eu não sabia que existia como, } \\
\text { por exemplo, o diafragma". }\end{array}$ \\
$\begin{array}{l}\text { uma escolha" } \\
\text { "O despertar } \\
\text { para o sonho" }\end{array}$ & 48,2 & $\begin{array}{l}\text { Aluno 20- "Me fez pensar na vida e nas escolhas que } \\
\text { devo tomar daqui em diante". } \\
\text { Aluno 67- "Eu acho que esse contribuiu, pois falou da } \\
\text { gravidez que às vezes resta dúvidas, sobre a } \\
\text { masturbação e a menstruação para conhecermos } \\
\text { melhor nosso corpo". }\end{array}$ \\
$\begin{array}{l}\text { relação sexual } \\
\text { engravida" }\end{array}$ & 45,5 &
\end{tabular}

Fonte: dados da pesquisa

Ao serem questionados sobre a importância de estudar o assunto sexualidade na escola, todos alegaram ser importante estudar o tema no âmbito escolar. Dessa forma, podemos perceber que os próprios alunos sabem da a necessidade de abordar assuntos relacionados à sexualidade no ambiente escolar.

Diante da avaliação sobre o uso dos jogos didáticos (Figura 1) como recurso didático para o ensino de Educação Sexual, foi perceptível que os alunos aprovaram os jogos, visto que fornecem um ambiente favorável e motivador e auxiliam no processo ensino-aprendizagem de forma clara e divertida. Esse resultado corrobora com os discursos dos alunos sobre as questões anteriores (Tabelas 2 e 3).

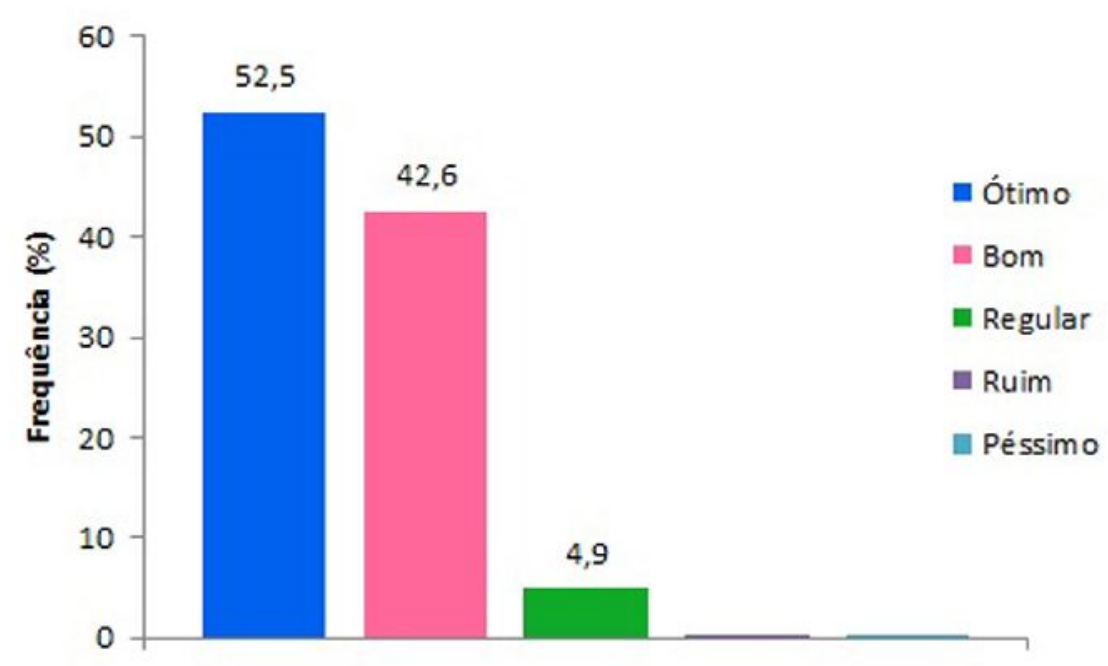

Figura 1. Avaliação dos alunos sobre os o uso de jogos didáticos sobre Educação Sexual. Fonte: Lorena Z. Bevitório

Alguns estudos utilizando jogos com a temática Educação Sexual relatam os aspectos positivos dos jogos como promotores da interação e construção compartilhada de conhecimentos, além da importância da ludicidade para a aprendizagem (OLIVEIRA et al., 2016; MORAES et al., 2018).

Os alunos deixaram suas sugestões para o uso de jogos didáticos nas aulas de Biologia (Tabela 4), sendo que a categoria mais frequente foi "ter mais vezes", 
demonstrando que os alunos aprovaram o uso de jogos e gostariam que fossem usados mais vezes, não só em assuntos relacionados à sexualidade, mas também em outros assuntos abordados na disciplina. Sugeriram também outros tipos de metodologias como uso de laboratórios, filmes e outros tipos de jogos.

Benine (2010) afirma que a utilização de jogos como ferramenta didática no ensino de Educação Sexual proporciona um clima favorável para aprendizagem, possibilitando o desenvolvimento da autonomia nos alunos frente à sexualidade. Além disso, a autora constatou que o uso de jogos didáticos no ensino de Educação Sexual foi aprovado pelos alunos que participaram da pesquisa.

Tabela 4. Sugestões dos alunos em relação ao uso de jogos didáticos nas aulas de Biologia.

\begin{tabular}{lcl}
\hline \multicolumn{1}{c}{ Categoria } & $\begin{array}{c}\text { Aluno } \\
(\%)\end{array}$ & \multicolumn{1}{c}{ Discursos } \\
\hline $\begin{array}{l}\text { Ter mais } \\
\text { vezes }\end{array}$ & 50 & $\begin{array}{l}\text { Aluno 31- "Eu acho que deveria continuar com esses } \\
\text { jogos, achei muito interessante e o desenvolvimento } \\
\text { na aula foi muito bom". }\end{array}$ \\
$\begin{array}{l}\text { Outras } \\
\text { metodologias }\end{array}$ & 19,7 & $\begin{array}{l}\text { Aluno 62- "Poderia haver aulas mais interativas, fora } \\
\text { da sala de aula, jogos sobre assuntos variados, aulas } \\
\text { no laboratório etc". } \\
\text { Sem }\end{array}$ \\
sugestões & 30,3 & Aluno 12- "Sem sugestões. Achei ótimo". \\
\hline Fonte: dados da pesquisa
\end{tabular}

Fonte: dados da pesquisa

Depois da utilização dos jogos didáticos do Projeto Vale Sonhar, alguns professores que lecionam na escola onde os jogos foram aplicados despertaram o interesse em utilizar essa metodologia no ensino de Educação Sexual. Espera-se que esses jogos possam ser utilizados por outros profissionais da educação, a fim de promover a saúde de crianças, adolescentes e jovens. Além de se apresentarem facilitadores na assimilação do conteúdo, potencializam o tempo do professor, já que os mesmos não necessitarão ser elaborados e construídos, sendo necessário apenas seguir as orientações do próprio kit.

\section{CONCLUSÃO}

O uso de jogos didáticos mostrou-se uma boa alternativa para trabalhar a temática educação sexual, visto que abordou o tema de forma interativa e divertida, proporcionando a aproximação do conteúdo didático com o cotidiano dos alunos, facilitando a abordagem e a interação entre o educador e aluno e entre os próprios alunos. É perceptível a carência de informações acerca do tema sexualidade, principalmente àquelas advindas dos próprios pais. Tratar de sexualidade é de responsabilidade principalmente dos pais, entretanto, na maioria dos casos, esse diálogo não ocorre e, assim, a família deixa de exercer influência na formação dos adolescentes. Dessa forma, a escola torna-se referência segura e crucial para a formação a respeito de sexualidade, sendo indispensável a abordagem dessa temática no ambiente escolar. 


\section{REFERÊNCIAS}

ANTUNES, C. Jogos para a estimulação das múltiplas inteligências. Petrópolis:Vozes, 2014, 312p.

ARAÚJO, A. V. S.; PINTO, M. B.; ANDRADE, L. D. F.; SANTOS, N. C. C. B. O papel dos pais na educação sexual de adolescentes: uma revisão integrativa. Revista da Universidade Vale do Rio Verde, v.13, n.2, p.117-128, 2015. Disponível em: http://periodicos.unincor.br/index.php/revistaunincor/article/view/2176/pdf_361

BARDIN, L. Análise de conteúdo. Lisboa: Edições 70, 1977, 225p.

BENINE, A. L. Jogos pedagógicos como estratégia para o ensino de educação sexual: experiência vivenciada nas aulas de ciências. Dissertação (Mestrado em ensino de Ciências e Matemática), Universidade de Cruzeiro do Sul, São Paulo, 2010, 116p.

BRASIL. Ministério da Educação. Secretaria de Educação Fundamental. Parâmetros Curriculares Nacionais: orientação sexual. Brasília: MEC/SEF, 1998. Disponível em: http://portal.mec.gov.br/

BRASIL. Ministério da Educação. Secretaria de Educação Básica. Orientações Curriculares para o Ensino Médio: Ciências da natureza, matemática e suas tecnologias. Brasília: MEC/SEB, 2006, v. 2. Disponível em: http://portal.mec.gov.br/

CARRARA, S. Moralidades, racionalidades e políticas sexuais no Brasil contemporâneo. Mana, v.21, n.2, p.323-345, 2015. Disponível em: http://dx.doi.org/10.1590/0104-93132015v21n2p323

INSTITUTO KAPLAN. Vale sonhar: livro do professor. São Paulo: Trilha Educacional, 2007, 66p.

KRABBE, E. C.; BRUM, M. D.; CAPELETTI, C. P.; COSTA, T. S.; MELLO, M. L.; VIEIRA, P. R.; CARVALHO, T. G. M. L. Escola, sexualidade, práticas sexuais e vulnerabilidades para as infecções sexualmente transmissíveis (IST). Revista Interdisciplinar de Ensino, Pesquisa e Extensão, v. 4, n,1, p.75-84, 2016. Disponível em: http://www.revistaeletronica.unicruz.edu.br/index.php/eletronica/article/view/4387/pdf -73

LARA, L. A. da S.; ABDO, C. H. N. Aspectos da atividade sexual precoce. Revista Brasileira Ginecologia Obstetrícia, v.37, n.5, p.199-202, 2015. Disponível em: http://www.scielo.br/scielo.php?script=sci_arttext\&pid=S0100-

$72032015000500199 \& \operatorname{lng}=e n \& n r m=i s o$.

MARTINS, I.C.P.; BRAGA, P.E.T. Jogo didático como estratégia para o ensino de divisão celular. Essentia, v.16, n.2, p.1-21, 2015. Disponível em: http://www.uvanet.br/essentia/index.php/revistaessentia/article/view/27/57 
MESSEDER NETO, H. S.; MORADILLO, E. F. O lúdico no ensino de química: considerações a partir da psicologia histórico-cultural. Química Nova na Escola, v.38, n.4, p.360-368, 2016. Disponível em: http://dx.doi.org/10.21577/01048899.20160048

MIRANDA, S. No fascínio do jogo, a alegria de aprender. Linhas Críticas, v.8, n.14, p.21-34, 2002. Disponível em: http://periodicos.unb.br/index.php/linhascriticas/article/view/2989 doi: https://doi.org/10.26512/lc.v8i14.2989.

MORAES, C. P.; CAMARGO, R. D.; ARAÚJO NETO, J.; PINHEIRO, R. C.; OLIVEIRA, N. D. Gravidez na adolescência e doenças sexualmente transmissíveis junto aos alunos dos $8^{\circ}$ s e $9^{\circ}$ s anos da E. E. Pirassununga, SP. Nucleus, v. 15, n.2, p.57-69, 2019. Disponível em: http://nucleus.feituverava.com.br/index.php/nucleus/article/view/2907/3083 doi: 10.3738/1982.2278.2907

NICOLA, J. A.; PANIZ, C. M. A importância da utilização de diferentes recursos didáticos no Ensino de Ciências e Biologia. InFor - Inovação e Formação, v.2, n.1, p.355-381, $2017 . \quad$ Disponível em: https://ojs.ead.unesp.br/index.php/nead/article/view/InFor2120167.

OLIVEIRA, S. N.; LIMA, A. C.; MENEZES, A. P. S. A utilização dos jogos de trilha como instrumento facilitador no ensino sobre o sistema genital humano, com alunos do $8^{\circ}$ ano. Arete - Revista Amazônica de Ensino de Ciências, Manaus, v.3, n.5, p. 66-79, 2010. Disponível em:

periodicos.uea.edu.br > index.php > arete > article > download.

OLIVEIRA, R. N. G.; GESSNER, R.; SOUZA, V.; FONSECA, R. M. G. S. Limites e possibilidades de um jogo online para a construção de conhecimento de adolescentes sobre a sexualidade. Ciência \& saúde coletiva, v.21, n.8, p.23832392, $2016 . \quad$ Disponível em: http://www.scielo.br/scielo.php?script=sci_arttext\&pid=S1413-

81232016000802383\&lng=pt\&tlng=pt - doi: https://doi.org/10.1590/141381232015218.04572016

OLIVEIRA, P.C.; PIRES, L. M.; JUNQUEIRA, A. L. N.; VIEIRA, M. A. S.; MATOS, M. A.; CAETANO, K. A. A. et al. Conhecimento em saúde sexual e reprodutiva: estudo transversal com adolescentes. Revista Eletrônica de Enfermagem [Internet], 19:17, 2017. Disponível em: http://dx.doi.org/10.5216/ree.v19.39926.

PALMA, Y. A.P.; PIASON, A. S.; MANSO, A. G.; STREY, M.N. Parâmetros curriculares nacionais: um estudo sobre orientação sexual, gênero e escola no Brasil. Temas em Psicologia, v.23, n.3, $2015 . \quad$ Disponível em:http://pepsic.bvsalud.org/scielo.php?script=sci_arttext\&pid=S1413389X2015000300016 doi: http://dx.doi.org/10.9788/TP2015.3-16

PIAGET, J. A. Formação do Símbolo na Criança. Rio de Janeiro:Zahar, 1978, 369p. 
SCHOEN-FERREIRA, T.H.; AZNAR-FARIAS, M.; SILVARES, E.F.M. Adolescência através dos séculos. Psicologia: Teoria e Pesquisa (online), v.26, n.2, p.227-234, 2010. Disponível em: http://www.scielo.br/scielo.php?pid=S010237722010000200004\&script=sci_abstract\&tlng=pt. doi: http://dx.doi.org/10.1590/S0102-37722010000200004.

VACARI, F. E. Abordagem metodológica para Conscientização e Prevenção da gravidez em adolescentes (Especialização em Ensino de Ciências) - Universidade Tecnológica Federal do Paraná, UTFPR, Medianeira, 2011, 40p.

VOLPATO, G. Jogo, brincadeira e brinquedo: usos e significados no contexto escolar e familiar. São Paulo: Annablume, 2017, 231 p. Disponível em: <http://www.unesc.net/portal/ capa/index/300/5886/ 